\title{
OUTCOME OF MYRINGOPLASTY WITH TEMPORALIS FASCIA AND PERICHONDRIAL-GARTILAGE GOMPOSITE GRAFT IN HIGH RISK PERFORATIONS
}

\author{
Dhungana A, Joshi RR, Rijal AS, Shrestha KK, Maharjan S
}

Department of Otorhinolaryngology \& Head and Neck Surgery, Nepal Medical College Teaching Hospital, Attarkhel, Gokarneshwor-8, Kathmandu, Nepal.

\begin{abstract}
The objective of this study was to compare the graft uptake results and postoperative hearing of myringoplasty with temporalis fascia and cartilage-perichondrial composite graft in high risk perforations. Patients of age 13 years and above with diagnosis of chronic otitis media - mucosal type with high risk perforation that is $>50 \%$ perforation of tympanic membrane, revision cases, absent/ eroded handle of malleus, oedematous/unhealthy middle ear mucosa and marginal involvement cases were included for myringoplasty. Pure Tone Audiometry was done within 1 week before surgery. 80 cases were included for myringoplasty which were randomly allocated by lottery method with 40 cases each in temporalis fascia group and cartilage perichondrial composite graft group. Graft uptake results were assessed after 6 weeks and postoperative hearing was evaluated and compared within and between the groups. Graft uptake rate in temporalis fascia group and cartilage perichondrial composite graft group was $90 \%$ and $92.5 \%$, respectively with no significance difference in the graft uptake rate $(p=0.692)$ between the groups. The mean pre and post-operative air bone gap in temporalis fascia group and cartilage perichondrial composite group were $30.69 \mathrm{~dB} \pm 10.19,16.36 \pm 8.37 \mathrm{~dB}$ and $33.73 \pm 8.07 \mathrm{~dB}, 20.76 \pm 9.47 \mathrm{~dB}$, respectively with highly significant difference in both groups $(\mathrm{p}<0.001)$ showing improvement in the hearing after surgery in both groups. The mean air bone gain were $14.33 \mathrm{~dB}$ and $12.97 \mathrm{~dB}$ in temporalis fascia and cartilage perichondrial composite group respectively with no significant difference between the groups ( $p=0.469)$. The graft uptake rate and hearing results after cartilage perichondrial composite graft are comparable to those of temporalis fascia graft. Furthermore, the cartilage perichondrial composite graft is more rigid and thick so it is more resistant than fascia to anatomic deformation and necrosis. Therefore, we recommend the use of cartilage perichondrial composite graft for tympanic membrane reconstruction in high risk perforation without concern about affecting audiometric results.
\end{abstract}

\section{KEYWORDS}

Cartilage-perichondrium, chronic otitis media, high risk perforation, myringoplasty, pure tone audiometry, temporalis fascia

\section{CORRESPONDING AUTHOR}

Dr. Anup Dhungana,

Lecturer, Department of ENT and HNS

Nepal Medical College Teaching Hospital,

Attarkhel, Gokarneshwor-8, Kathmandu, Nepal,

Email: dhunganaanup@hotmail.com 


\section{INTRODUCTION}

Myringoplasty is repair of tympanic membrane. It is one of the common surgery done in otology for the treatment of Chronic Suppurative Otitis MediaTubotympanic Type(CSOM-TT). ${ }^{1}$

In 1952, Wullstein ${ }^{2}$ and Zollner $^{3}$ first described tympanoplasty as the mainstay for tympanic membrane reconstruction. Various grafting materials have been used for reconstruction like mesenchymal tissues, including vein, fascia, perichondrium and periosteum..$^{4-10}$ Nowadays most frequently used graft material is temporalis muscle fascia. ${ }^{11}$

Cartilage was first used by Jansen ${ }^{12}$ in 1958 for ossicular chain reconstruction. Then in 1963, Salen ${ }^{13}$ and Jansen ${ }^{14}$ used cartilage composite grafts for tympanic membrane reconstruction.

Since the first description of tympanoplasty, clinicians have encountered different complications like recurrent tympanic membrane retraction and reperforation and attempted to reduce the frequency of complications. ${ }^{15}$ In cases like revision tympanoplasty and atelectatic ear, cartilage has been used with great success to reconstruct the tympanic membrane. Cartilage has been shown to be well tolerated by middle ear and long term survival is achieved since cartilage graft is nourished largely by diffusion. Even in the cases of severe Eustachian tube dysfunction, cartilage maintains its rigid quality and resists resorption and retraction but due to its opacity, it is difficult to visualize middle ear. ${ }^{16-21}$

Various techniques of cartilage tympanoplasty have been described: Inlay butterfly graft ${ }^{22}$,
Perichondrium/cartilage island graft, ${ }^{16}$ Palisade technique $^{23}$ and Cartilage shield technique. ${ }^{21}$

In this study, we are trying to compare the results of Myringoplasty with Temporalis Fascia graft and Perichondrial-cartilage composite graft harvested from the tragus in high risk perforations i.e. subtotal or total perforation of TM, patient with $>50 \%$ perforation of TM, revision cases, anterior margin involvement, absent/partially eroded handle of malleus, presence of pus/discharge in middle ear and epithelial ingrowth. ${ }^{24-31}$

\section{MATERIALS AND METHODS}

This prospective, comparative, analytical study was done in Nepal Medical College Teaching Hospital, Department of Otorhinolaryngology and Head and Neck Surgery from March 2015 to Feb 2017.

Patients aged 13 years and above diagnosed with COM mucosal type with high risk perforation willing to undergo myringoplasty in the hospital were included in the study. High risk perforation was defined as patients with subtotal or total perforation of $\mathrm{TM},>50 \%$ perforation of $\mathrm{TM}$, revision cases, anterior margin involvement, absent/partially eroded handle of malleus and presence of pus/ discharge in middle ear. Patient with frank otorrhea, small perforation equal to or less than $50 \%$ and patients with sensorineural hearing loss were excluded from the study.

Randomisation was done by lottery method. Results were analysed as graft uptake rate and change between pre- and post-operative hearing. Data were analyzed using Fisher's exact test,

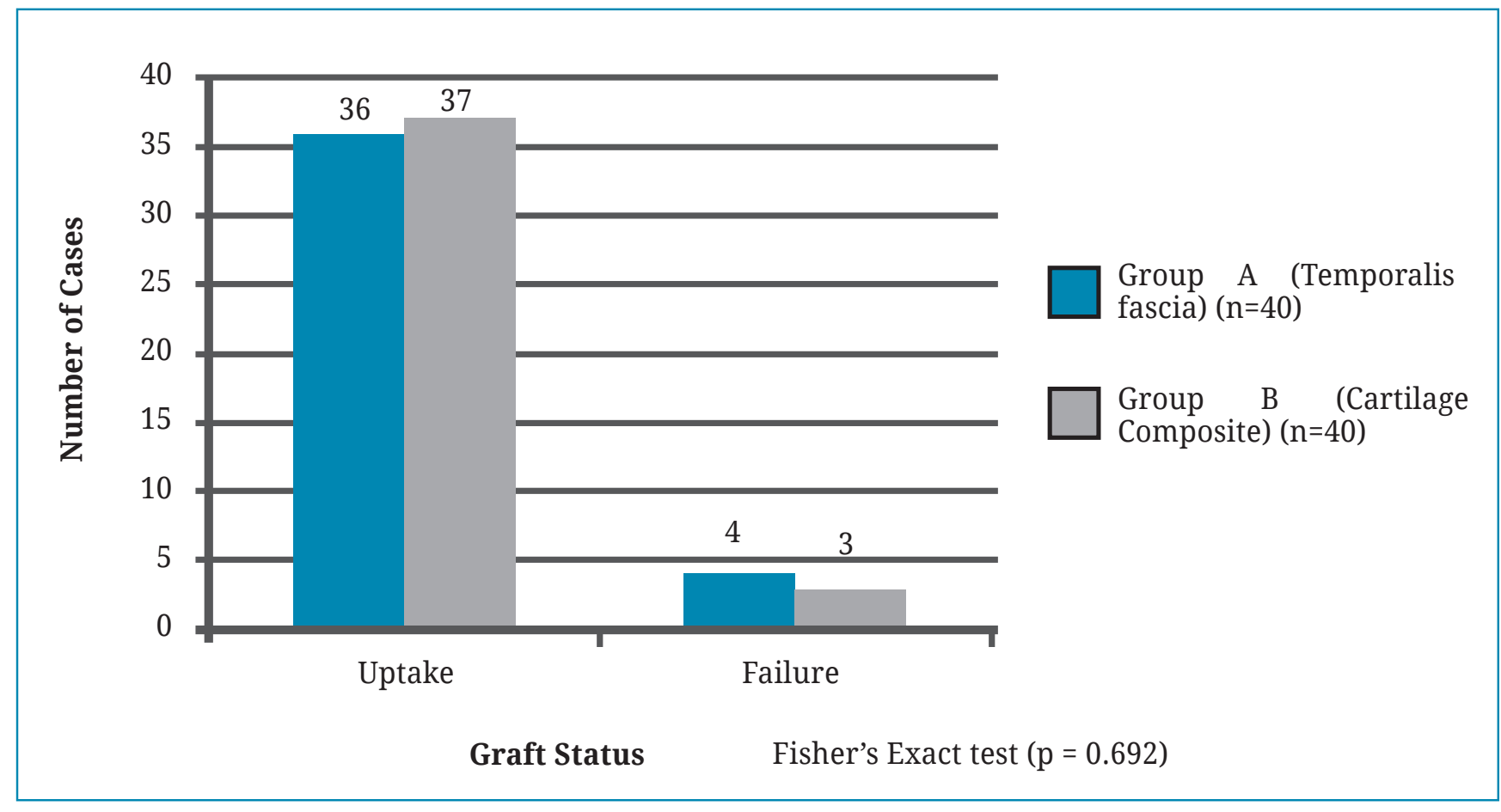

Fig. 1: Post-operative graft status in two groups 
Chi square test, dependent and independent ' $t$ ' test on a SPSS statistical package version 16.0. The level of statistical significance was set at $p<0.05$. Ethical approval was taken from the Institutional Review Committee (IRC) of Nepal Medical College.

\section{RESULTS}

Total number of patients enrolled for the study was 84. These patients were randomized into two groups temporalis fascia group (Group A) and perichondrial-cartilage composite graft (Group B) by lottery method, each group containing 42 patients. Out of them 4 were excluded from the study due to loss to follow up, 2 from each group with remaining 40 patients in each group.
$14.33 \mathrm{~dB}$ and $12.97 \mathrm{~dB}$ in fascia group (group A) and cartilage group (group B) respectively. Applying independent T-test, the difference in means between the groups in each category was found to be not significant statistically (Table-1).

\section{DISCUSSION}

Myringoplasty is a commonly done surgical procedure. In our study, out of 80 cases 38 were male and 42 were female. In our study, graft uptake rate was $90.0 \%$ in temporalis fascia group and $92.5 \%$ in perichondrial cartilage group which is similar to Yung et al ${ }^{24}$ who found the graft uptake rates of fascia and cartilage grafts at 24 months were $84.2 \%$ and $80 \%$, respectively.

Table-1: Comparison of pre- and post-operative hearing between two groups

\begin{tabular}{|lccc|} 
Mean & $\begin{array}{c}\text { Group A (Temporalis } \\
\text { fascia) }\end{array}$ & $\begin{array}{c}\text { Group B (Cartilage } \\
\text { composite) }\end{array}$ & P value \\
Pre-operative PTA-AC threshold (dB) & 47.72 & 49.95 & 0.407 \\
Post-operative PTA-AC threshold (dB) & 32.39 & 35.30 & 0.313 \\
Pre-operative PTA-AB Gap (dB) & 30.69 & 33.73 & 0.162 \\
Post-operative PTA-AB Gap (dB) & 16.36 & 20.76 & 0.064 \\
ABG gain $(\mathrm{dB})$ & 14.33 & 12.97 & 0.469 \\
\hline
\end{tabular}

In temporalis fascia group (Group A), there was graft uptake in $36(90 \%)$ cases and failure in $4(10 \%)$ cases whereas in cartilage composite group (Group B), graft uptake was observed in $37(92.5 \%)$ cases and failure in $3(7.5 \%)$ cases. The difference in graft uptake results between these two groups was not found to be statistically significant ( $p=0.692$ ) (Fig. 1).

For the comparison of hearing results, only 36 cases with graft uptake were taken in this group A. The mean pre-operative air conduction threshold was $47.72 \mathrm{~dB}(\mathrm{SD}=13.39)$ and post-operative air conduction threshold was $32.39 \mathrm{~dB}(\mathrm{SD}=13.97)$. The mean preoperative air bone gap was $30.69 \mathrm{~dB}(\mathrm{SD}=10.19)$ and post-operative air bone gap was $16.36 \mathrm{~dB}(\mathrm{SD}=8.37)$. Hearing improvement after surgery was found to be statistically highly significant $(p<0.001)$. For the comparison of hearing results in this group B, only 37 cases with graft uptake were taken. The mean pre-operative air conduction threshold was 49.95 $\mathrm{dB} \quad(\mathrm{SD}=9.01)$ and post-operative air conduction threshold was $35.30 \mathrm{~dB}(\mathrm{SD}=10.27)$. The mean preoperative air bone gap was $33.73 \mathrm{~dB}(\mathrm{SD}=8.07)$ and post-operative air bone gap was $20.76 \mathrm{~dB}(\mathrm{SD}=9.47)$. Hearing improvement after surgery was found to be statistically highly significant $(p<0.001)$.

The mean pre-operative Pure Tone Audiogram -Air Conduction (PTA-AC) threshold was found to be 47.72 $\mathrm{dB}$ and $49.95 \mathrm{~dB}$, post-operative PTA-AC threshold was $32.39 \mathrm{~dB}$ and $35.30 \mathrm{db}$, pre-operative Pure Tone Audiogram-Air Bone (PTA-AB) Gap was $30.69 \mathrm{db}$ and $33.73 \mathrm{~dB}$, post-operative PTA-AB Gap was 16.36 $\mathrm{dB}$ and $20.76 \mathrm{~dB}$ and mean Air Bone (AB) gain was
Yung et $a 2^{24}$ found postoperative air-bone gaps and hearing gains at 24 months were $16.97 \mathrm{~dB}$ and 13.63 $\mathrm{dB}$, respectively, in the fascia group and $20.63 \mathrm{~dB}$ and $12.60 \mathrm{~dB}$, respectively, in the cartilage group. There was no significant difference in the graft uptake rates or postoperative hearing between the two groups. This is similar to our study, which was $16.36 \mathrm{~dB}$ and $14.33 \mathrm{~dB}$ in the fascia group and 20.76 $\mathrm{dB}$ and $12.97 \mathrm{~dB}$ respectively in cartilage group.

Haitham et al ${ }^{25}$ included 40 patients, 23 males and 17 females. The average age of patients is 28.4 years with a range from 13-55 years. Surgical success rates for the temporalis fascia and cartilage groups are $77.78 \%$ and $95.45 \%$, respectively. There is $19.4 \mathrm{~dB}$ improvement in mean hearing threshold in fascia group, compared to $15.2 \mathrm{~dB}$ improvement in cartilage group, giving an average of $17 \mathrm{~dB}$ improvement in mean hearing threshold of the total series. The finding of this study is comparable to our study but the number of cases are more in our study.

Gerber et $a^{26}$ demonstrated that hearing results after cartilage tympanoplasty are comparable to those after temporalis fascia tympanoplasty. Therefore, when indicated, a cartilage-perichondrium graft can be used for prevention of disease recurrence or progression without fear of impairing hearing. Gamra et $a^{27}$ achieved successful closure of the tympanic membrane perforation in $97 \%$ of the cartilage group as compared to $94 \%$ of the fascia group. The average Air Conduction Gain (ACG) was $21 \pm 11 \mathrm{~dB}$ in cartilage group and $20 \pm 22 \mathrm{~dB}$ in fascia group. With an average follow-up of 2 years, residual 
perforation was observed in $2.2 \%$ in cartilage group. Reperforation of fascia graft and retraction were noted in 2.1 and 1\%, respectively. Dornhoffer et al ${ }^{28}$ reports 96 patients who failed at least 1 temporalis fascia graft tympanoplasty, of which 29 of them also underwent ossicular chain reconstruction. TM closure was achieved in about 95\% of patients. There was a significant improvement in pure tone audiogram (PTA) from 24.6 to $12.2 \mathrm{~dB}$.

Khullar et $a l^{29}$ found tympanoplasty type I using temporal fascia was successful in 17 (74\%) ears while tympanoplasty using composite cartilage graft was successful in 20 (91\%) ears. Composite graft procedure gave better functional improvement, helped in reconstruction of canal wall and was useful in elimination of retraction pockets. Therefore composite cartilage tympanoplasty offers possibility of a rigorous tympanic membrane reconstruction.

Akihiro et $\mathrm{al}^{30}$ suggest that use of perichondrium with cartilage composite graft is advantageous for second operation or perforation of the eardrum. Couto et al ${ }^{31}$ found the tragus cartilage inlay myringoplasty with cartilage resembling butterfly wings has a high rate of success to close tympanic membrane perforations with $5 \mathrm{~mm}$ diameter at the most in cases of chronic otitis media with healthy middle ear and gives more patient comfort with less morbidity.

All these above findings show the hearing results are comparable between the cartilage composite graft and temporalis fascia graft. This removes the doubt that cartilage, because of its rigidity and mass, greatly affects post-operative hearing results.

Our study addresses only short-term graft uptake and audiologic results which may change with time. Although evidence suggests that the post-operative hearing actually improves with time in cases of cartilage myringoplasty, ${ }^{22}$ a longitudinal followup of this patient group is anticipated in order to elucidate the long-term viability of this technique.

The graft uptake rate and hearing results after cartilage perichondrial composite graft are comparable to those of temporalis fascia graft. Furthermore, the cartilage perichondrial composite graft is more rigid and thick so it is more resistant than fascia to anatomic deformation and necrosis. Therefore, we recommend the use of cartilage perichondrial composite graft for tympanic membrane reconstruction in high risk perforation without concern about affecting audiometric results.

\section{REFERENCES}

1. Slattery III WH. Pathology and clinical course of inflammatory disease of middle ear. GlasscockShambaugh Surgery of the ear, $5^{\text {th }}$ edition. New Delhi, Elsvier India; 2003: 422-33.

2. Wullstein HL. Functional operations in middle ear with split-thickness skin graft. Arch Otorhinolaryngol 1952; 161: 422-35.

3. Zollner F. The principles of plastic surgery of the sound-conducting apparatus. J Laryngol Otol 1955; 69: 657-9.

4. Shea JJ. Vein graft closure of eardrum perforations. J Laryngol Otol 1960; 74: 358-62.

5. Tabb HG. Closure of perforations of the tympanic membrane by vein grafts: a preliminary report of 20 cases. Laryngoscope 1960; 70: 271-4.

6. Heerman H. Tympanic membrane plastic repair with temporalis fascia. Hals Nas Ohrenh 1960; 9: 136-9.

7. Salen B. Tympanic membrane grafts of fullthickness skin, fascia and cartilage with its perichondrium, an experimental and clinical investigation. Acta Otolaryngol Suppl Stockh 1968; (Suppl) 244: 5-73.

8. Claros-Domenech A. 100 tympanoplasties practiced with the aid of the use of free periosteal membrane graft (in French). Rev Laryngol Otol Rhinol (Bord.) 1959; 80: 917-21.

9. Bocca E, Cis C, Zernotti E. L'impiego di lembi liberi di periostio nella tympanoplastica. Arch Ital Otol 1959; (Suppl) 40: 205.
10. Nissen AJ, Nissen RL, Yonkers AJ. A historical review of the use of bone and cartilage in otologic surgery. Ear Nose Throat J 1986; 65: 493-6.

11. Glasscock ME, House WF. Homograft reconstruction of the middle ear. Laryngoscope 1968; 78: 1219-25.

12. Jansen $C$. The use of cartilage in hearing restorative operations (in German). 7th Int'l Congr Otol Rhinol Laryngol; Paris, France; 1961.

13. Salen B. Myringoplasty using septum cartilage. Acta Otolaryngol 1963; (Suppl) 188: 82-91.

14. Jansen C. Cartilage-tympanoplasty. Laryngoscope 1963; 73: 1288-302.

15. Buckingham RA. Fascia and perichondrium atrophy in tympanoplasty and recurrent middle ear atelectasis. Ann Otol Rhinol Laryngol 1992; 101: 755-8.

16. Glasscock ME, Jackson CG, Nissen AJ, Schwaber MK. Postauricular undersurface tympanic membrane grafting: a follow-up report. Laryngoscope 1982; 92: 718-27.

17. Levinson RM. Cartilage-perichondrial composite graft tympanoplasty in the treatment of posterior marginal and attic retraction pockets. Laryngoscope 1987; 97: 1069-74.

18. Adkins WY. Composite autograft of tympanoplasty and tympanomastoid surgery. Laryngoscope 1990; 100: 244-7.

19. Milewski C. Composite graft tympanoplasty in the treatment of ears with advanced middle ear 
pathology. Laryngoscope 1993; 103: 1352-6.

20. Poe DS, Gadre AK. Cartilage tympanoplasty for management of retraction pockets and cholesteatomas. Laryngoscope 1993; 103: 614-8.

21. Duckert LG, Muller J, Makielski KH, Helms J. Composite autograft 'shield' reconstruction of remnant tympanic membranes. Am J Otol 1995; 16: 21-6.

22. Eavey RD. Inlay tympanoplasty: cartilage butterfly technique. Laryngoscope 1998; 108: 657-61.

23. Heermann J Jr, Heermann H, Kopstein E. Fascia and cartilage palisade tympanoplasty. Nine years' experience. Arch Otolaryngol 1970; 91: 228-41.

24. Yung M, Vivekanandan S, Smith P. Randomized study comparing fascia and cartilage grafts in myringoplasty. Ann Otol Rhinol Laryngol 2011; 120: 535-41.

25. Haitham AA, Ali AMM, Raghdan MA, Khalid DH. Temporalis fascia versus cartilage graft in myringoplasty. Jordan Med J 2014; 48: 113-20.
26. Gerber MJ, Mason JC, Lambert PR. Hearing results after primary cartilage tympanoplasty. Laryngoscope 2000; 110: 1994-9.

27. Ben Gamra O, Mbarek C, Khammassi K, Methlouthi N, Ouni H, Hariga I, Zribi S, Koubâa J, El Khedim A. Cartilage graft in type I tympanoplasty: audiological and otological outcome. Eur Arch Otol Rhinol Laryngol 2008; 265: 739-42.

28. Dornhoffer J. Hearing results with cartilage tympanoplasty. Laryngoscope 1997; 107: 1094-9.

29. Khullar NK, Kotwal S, Paul J. Composite graft tympanoplasty. JK Practitioner 2000; 7: 121-4.

30. Akhihiro K, Yumi M, Tadashi D, Hiromichi K, Masayuki F, Mototane K, Toshio Y, Yasuo H. Results and devices of simple myringoplasty with fibrin glue. Otology Japan 2006; 16: 81-6.

31. Couto L, Marquezini RMS, Oliveira JA, Massuda ET. Outcome of inlay tragus cartilage myringoplasty. Braz J Otolaryngol 2004; 70: 494-8. 